\title{
Diagnóstico de má oclusão de Classe III por alunos de graduação
}

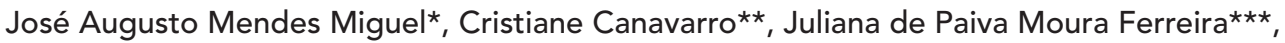
Ione Helena Portella Brunharo ${ }^{\star \star \star \star}$, Marco Antonio de Oliveira Almeida ${ }^{\star \star \star \star \star}$

\section{Resumo}

Objetivo: verificar a capacidade de alunos de graduação diagnosticarem a má oclusão do tipo Classe III de Angle, assim como avaliar a possível indicação para tratamento ortodôntico e o momento ideal de iniciá-lo, levando em consideração as idades dentária e esquelética do paciente. Métodos: a amostra foi composta por 138 alunos do último período de graduação de 10 faculdades de Odontologia do estado do Rio de Janeiro, avaliados por meio de questionários com perguntas fechadas. Foram-lhes apresentados fotografias e modelos de estudo de um paciente portador de má oclusão Classe III de Angle unilateral e, ainda, outras más posições dentárias. Resultados: constatou-se facilidade por parte dos estudantes em identificar o desvio de linha média ( $\mathrm{n}=124$ ou 90\%) e a mordida cruzada anterior ( $\mathrm{n}=122$ ou 89\%). Em contrapartida, aproximadamente metade da amostra ( $n=63$ ou $46 \%$ dos alunos) foi capaz de reconhecer, no caso clínico, a existência da má oclusão Classe III de Angle unilateral. Apenas $46 \%$ deles $(n=63)$ identificaram a ausência precoce do dente decíduo. Quanto ao tratamento, quase a totalidade concordou com a sua necessidade, porém encontraram dificuldade em reconhecer o momento ideal da indicação ao especialista, com a finalidade de que este realize o tratamento ortodôntico. Conclusão: os estudantes terminam o curso de graduação com dificuldade no diagnóstico de Classe III e nem mesmo articulam idéias sobre um protocolo básico de tratamento para correção desta anormalidade.

Palavras-chave: Ortodontia interceptora. Diagnóstico. Má oclusão Classe III de Angle.

\section{INTRODUÇÃO}

O processo de decisão clínica a partir do diagnóstico ortodôntico e formulação do plano de tratamento envolve: o reconhecimento das características das más oclusões e deformidades dentofaciais, a definição da causa do problema e a formulação de uma estratégia de tratamento baseada nas necessidades específicas do paciente.

O diagnóstico em Ortodontia deve ser direcionado de acordo com a lista de problemas apresentados pelo paciente. A classificação de Angle, por ser simples e largamente conhecida pela comunidade odontológica, continua sendo amplamente utilizada. No entanto, devido às suas limitações,

\footnotetext{
* Doutor em Epidemiologia pela UFRJ. Mestre em Odontopediatria pela UERJ. Professor adjunto e coordenador do curso de mestrado em Ortodontia da FO-UERJ.

** Mestre e doutoranda em Ortodontia pela FO-UERJ.

*** Especialista em Ortodontia pela FO-UERJ.

**** Doutora em Ortodontia pela FO-UERJ.

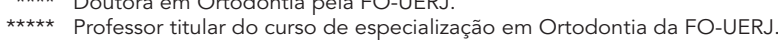


os aspectos verticais, transversos e até mesmo o perfil facial e problemas de espaço devem ser considerados para obtenção de um diagnóstico preciso, levando a uma correta conduta terapêutica.

De acordo com experiências clínicas, a má oclusão de Classe III deve ser tratada o mais cedo possível, com o objetivo de restringir todo o crescimento horizontal ou, pelo menos, redirecioná-lo a um vetor mais vertical, deixando que a maxila continue o seu crescimento para baixo e para frente. Se o ortodontista conseguir este vetor mais vertical, deve considerar que obteve um grande sucesso $^{27}$. Sua incidência tem sido descrita como de, aproximadamente, $5 \%$ nos caucasianos, enquanto nas populações japonesa, escandinava e chinesa é proporcionalmente maior ${ }^{8}$. No Brasil, de acordo com uma pesquisa realizada na região de Bauru, estima-se uma prevalência da Classe III em torno de $3 \%{ }^{24}$.

Considerando que é objetivo do ensino da graduação em Odontologia formar cirurgiões-dentistas capazes de reconhecer as características do desenvolvimento normal da oclusão dentária e identificar os diferentes tipos de má oclusão, assim como o momento ideal para intervenção, este trabalho foi realizado com o intuito de avaliar a conduta clínica dos estudantes frente a um paciente com má oclusão de Classe III de Angle e, conseqüentemente, a eficiência do ensino na área de Ortodontia das Faculdades de Odontologia do Rio de Janeiro.

\section{REVISÃO DE LITERATURA}

Durante anos, a Classe III esquelética e o prognatismo mandibular foram relacionados como sendo sinônimos, o que caracterizava a mandíbula como o componente ósseo diretamente envolvido no desenvolvimento da anomalia craniofacial. Hoje, sabe-se que vários tipos de padrões de combinação esquelética podem compor indivíduos com esta condição: o prognatismo mandibular, a retrusão maxilar ou a combinação de ambos podem ser a etiologia do problema ${ }^{5,8}$. Alguns estudos demonstraram que, em média, $65 \%$ das más oclu- sões de Classe III estão associados a uma deficiência maxilar e que em 30\% essa retrusão é devida a uma protrusão mandibular ${ }^{5,13}$.

Acreditava-se que a terapia ortodôntica para o tratamento da Classe III deveria se limitar a conter a protrusão mandibular e o aparelho eleito, normalmente, era a mentoneira. Sugawara et al. ${ }^{25}$, em 1990, verificaram que este aparelho produz um deslocamento maxilar para baixo e para frente, associado a um giro da mandíbula para baixo e para trás. No entanto, após o surto de crescimento, pacientes pertencentes ao grupo teste que utilizou mentoneira apresentaram resultados semelhantes aos do grupo controle.

Mitani, Mitani e Furkazawa ${ }^{17}$, em 1986; Ritucci , Ritucci e Nanda ${ }^{22}$, em 1986, e Sugawara ${ }^{25}$, em 1990, concordaram que é praticamente impossível inibir o crescimento mandibular através da utilização da mentoneira, pois o potencial de crescimento inerente parece ter um papel mais decisivo. Em virtude disso, os ortodontistas evitavam, ao máximo, o tratamento precoce, por acreditarem que o prognatismo mandibular fosse a causa primária - e a impossibilidade do seu controle tornava o tratamento cirúrgico inevitável.

$\mathrm{O}$ advento do conceito do envolvimento maxilar influenciou drasticamente a abordagem terapêutica, sendo impreterível o diagnóstico e o tratamento precoces ${ }^{28}$. A má oclusão de Classe III decorrente de uma retrusão maxilar, ou mesmo de uma leve ou moderada protrusão mandibular, tem bom prognóstico frente ao tratamento precoce, que deve ser iniciado na dentadura decídua ou início da mista, antes do surto de crescimento puberal ${ }^{13}$.

Turpin $^{29}$, em 1981, propôs um protocolo de orientação de acordo com características clínicas e cefalométricas que são positivas ou negativas a um tipo de tratamento precoce. As características positivas constituem: tipo facial convergente, deslocamento funcional ântero-posterior, crescimento condilar simétrico, paciente jovem (com crescimento remanescente), desarmonia esquelé- 
tica média (ANB > -2), boa cooperação, ausência de prognatismo familiar e boa estética facial. Por outro lado, as características indicativas de negatividade são: tipo facial divergente, sem deslocamento ântero-posterior, crescimento assimétrico, crescimento finalizado, desarmonia esquelética severa (ANB $<-2$ ), pouca cooperação, padrão familiar estabelecido e estética facial pobre.

O tratamento precoce atualmente preconizado compreende uma disjunção palatina prévia a uma protração da maxila ${ }^{14}$. Capelozza Filho et al. ${ }^{2}$, em 2002, levantaram a hipótese de que o desarranjo criado nas relações entre a maxila e a mandíbula, com a expansão rápida da maxila e a tração da mesma, produz um incremento de crescimento maxilar significativo e um desajuste funcional que perturba a plena manifestação do crescimento mandibular.

Haas (1961, apud NGAN $\left.{ }^{19}, 1996\right)$ indicou a expansão rápida da maxila em indivíduos com má oclusão de Classe III cirúrgica e não-cirúrgica, com deficiência maxilar real ou relativa. Ressaltou que, com a expansão da maxila, ocorre uma separação da sutura mediana, com conseqüente deslocamento do ponto A para baixo e para frente. Ao se fazer a associação deste procedimento com a máscara facial, maior deslocamento pode ser obtido, pois a maxila apresenta-se mais suscetível à atuação de forças ortopédicas, pois ocorre também um efeito sobre as suturas maxilares ${ }^{2}$. Viazis ${ }^{30}$, em 1993, recomendou o uso do aparelho de disjunção palatal antes de iniciar a protração reversa da maxila, como uma forma de "desarticulá-la" e, com isso, facilitar o seu movimento para anterior. A dissociação sutural da maxila acaba produzindo um aumento da atividade celular das suturas circunmaxilares, acentuando a largura transversa da maxila e o efeito da protração do osso maxilar ${ }^{14,28}$.

Para este tratamento precoce, que é do tipo ortopédico, indica-se dois tipos de expansores palatinos: o aparelho de Haas adaptado para dentadura decídua e mista, pois este suporta e distribui equilibradamente as forças transmitidas pelo aparelho extrabucal; ou o aparelho Hyrax, que apresenta a mesma ação e eficácia que o Haas na região da sutura palatina, porém parece ser mais facilmente confeccionado, por se tratar de um aparelho pré-fabricado, diminuindo a hora laboratorial do profissional (este não possui a parte de apoio acrílico no palato, facilitando, assim, a higienização e impedindo o aparecimento de lesões nesta localidade, no decorrer das ativações $)^{4}$. A ativação do parafuso expansor deve ser iniciada com $3 / 4$ de volta, para torná-lo um aparelho ortopédico, depois faz-se necessária uma ativação de $1 / 4$ de volta de dia e $1 / 4$ de volta à noite, até que a separação dos incisivos centrais superiores evidencie clinicamente a expansão maxilar. A partir disso, o parafuso expansor será ativado apenas $1 / 4$ de volta por $\mathrm{dia}^{2}$.

Quanto ao aparelho extrabucal, podemos utilizar o Sky-hook, preconizado por Hickhan em 1972 (mentoneira com ganchos verticais), ou a máscara facial, que pode ser a de Delaire (1971), Petit (1998) ou ainda a de Turley (1988). Optar por um ou outro aparelho dependerá das relações proporcionais verticais, pois a máscara facial produz maior componente vertical, incrementando a altura facial inferior ${ }^{2}$. É importante citar que elásticos são colocados partindo de ganchos situados no aparelho expansor, que se encontram próximos dos caninos superiores, até os ganchos na máscara facial, promovendo uma tração para baixo e para frente da maxila ${ }^{7}$. No que diz respeito às forças aplicadas, não existe unanimidade entre os autores, sendo que Oppenhein ${ }^{20}$ (1944) preconizou uma força de $110 \mathrm{~g}$ para uso noturno, $\mathrm{Nanda}^{18}$ (1980) utilizou de 500 a $750 \mathrm{~g}$ num período de 20 a 22 horas por dia, Turley ${ }^{28}$ (1988) adotou forças que variam de 150 a $600 \mathrm{~g}$ nas 24 horas do dia, McNamara $^{14}$ (1987) prescreveu uma força de $450 \mathrm{~g}$ durante 24 horas por dia e Hickham ${ }^{10}$ (1991) indicou que a protrusão maxilar requeria de 600 a $800 \mathrm{~g}$ de força durante o dia todo.

Mediante a protração da maxila, pode-se observar o movimento da maxila para frente e para baixo, giro da mandíbula no sentido horário, aumento 
do $1 / 3$ inferior da face, melhora do perfil 12,13,19,23, verticalização dos incisivos inferiores ${ }^{12,15,19,24}$ e aumento da inclinação vestibular dos incisivos superiores ${ }^{12,15,19,23,26}$.

Após esta etapa primária de tratamento, o indivíduo deve ser observado clínica e radiograficamente para uma reavaliação no grau de recolocação maxilar, no redirecionamento do crescimento mandibular e no estabelecimento das relações oclusais estáveis. A segunda fase do tratamento deve ser muito bem conduzida e um dos seus pontos principais é a avaliação quanto ao potencial de crescimento do paciente, devendo-se aguardar o término do surto puberal, com o objetivo de evitar recidiva durante ou após o tratamento. A ocorrência da recidiva pode dificultar o caso de maneira significativa, principalmente quando este envolve extrações. Este cuidado permite um planejamento adequado, que será realizado com camuflagem ou cirurgia ortognática, de acordo com a situação real do paciente ao término do crescimento.

A segunda conduta é a montagem da aparatologia fixa e, nos casos favoráveis, é iniciado o tratamento ortodôntico, objetivando compensações dentárias que resultem na camuflagem da Classe III, evitando a cirurgia ortognática. Nos casos em que estes resultados sejam insatisfatórios, deve-se optar pelo preparo ortodôntico para a cirurgia, aguardando a época ideal para a realização deste procedimento, em torno de 18 anos para pacientes do gênero feminino e 21 para os do gênero masculino ${ }^{27}$.

Embora cronologicamente possa ser considerada longa, essa terapia é realizada em fases, concordando com a moderna filosofia ortodôntica de adequar, inicialmente, as bases ósseas e, posteriormente, realizar a Ortodontia corretiva, determinando uma relação custo-benefício positiva para o tratamento.

Cabe lembrar aqui o papel dos aparelhos funcionais, os quais poderiam ser indicados para o tratamento da condição de Classe II na dentadura decídua e mista, porém não possuem a mesma aplicabilidade na má oclusão de Classe III, não sendo indicados no tratamento destes $\operatorname{casos}^{7} . \mathrm{Na}$ terapia para tratamento da Classe III associada a uma deficiência maxilar, um tipo de aparelho muito utilizado na Ortopedia Facial é o Regulador Funcional de Fränkel III, ou simplesmente FR-3. O aparelho é composto por escudos vestibulares, que eliminam a pressão muscular, e amortecedores labiais superiores, com a finalidade de conter a ação dos músculos mastigatórios circundantes, que restringem o crescimento para frente da maxila e retraem os dentes superiores ${ }^{6}$. A utilização do FR-3 em detrimento da terapia com a máscara facial é prejudicial em dois aspectos: o primeiro é que este aparelho funcional demora de 12 a 24 meses para produzir algumas das modificações atribuídas ao seu uso constante, enquanto a máscara facial corrige esta condição em apenas seis meses de emprego; o segundo aspecto é que, obviamente, o FR-3 tem um efeito muito maior sobre os tecidos moles associados à maxila do que propriamente um efeito esquelético, como o encontrado na máscara facial. Portanto, sua indicação não é para correção e sim como uma terapia iniciadora na dentadura decídua ou, ainda, como contenção de uso noturno pós-terapia com a máscara ortopédica facial ${ }^{17}$. Outros aparelhos, tais como o Bionator de Balters e o Arco de Escheler ou Progenie, quando empregados no tratamento da Classe III, única e exclusivamente na dentadura decídua, produzem a retroinclinação dos incisivos inferiores e a vestibularização dos incisivos superiores, introduzindo um elemento de camuflagem dentária para uma discrepância esquelética. Podese, também, notar uma melhora na posição espacial da mandíbula (movimento para baixo e para trás). Em relação à maxila, o que ocorre é uma liberação para o seu crescimento e não uma protração ou avanço desta ${ }^{21}$.

\section{MATERIAL E MÉTODOS}

A amostra foi composta, aleatoriamente, por 138 alunos do último período de graduação de 10 
escolas de Odontologia do estado do Rio de Janeiro, sendo estas: Faculdade de Odontologia de Campos, Universidade do estado do Rio de Janeiro, Universidade Federal Fluminense, Universidade Federal do Rio de Janeiro, Universidade Gama Filho, Universidade Estácio de Sá, Universidade de Volta Redonda, Universidade de Nova Iguaçu, Universidade do Grande Rio e Universidade Veiga de Almeida.
Foi utilizada a técnica padronizada de coleta de dados, através de questionário, o qual vinha anexado ao caso clínico. Estes foram apresentados a todos os alunos do último período que estavam presentes no dia da visita, individualmente e sem limitação de tempo para responder as questões. A documentação dos pacientes consistia apenas de fotos de frente e perfil da face e modelos
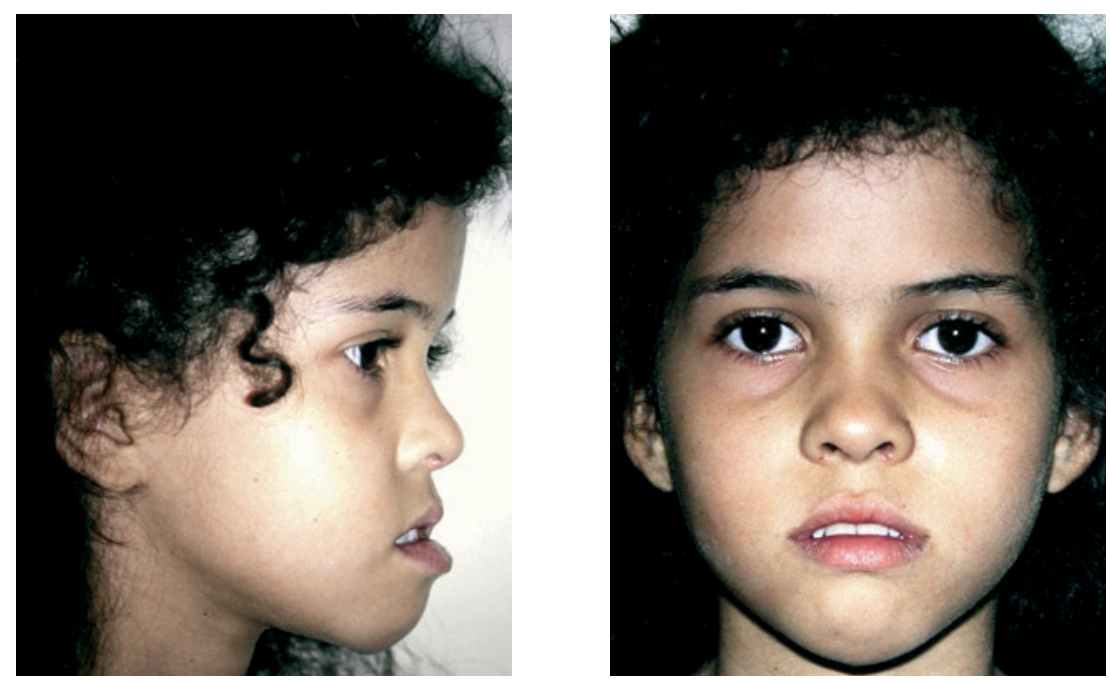

FIGURA 1 - Fotografias de perfil e de frente da paciente cujo caso clínico foi apresentado aos alunos.
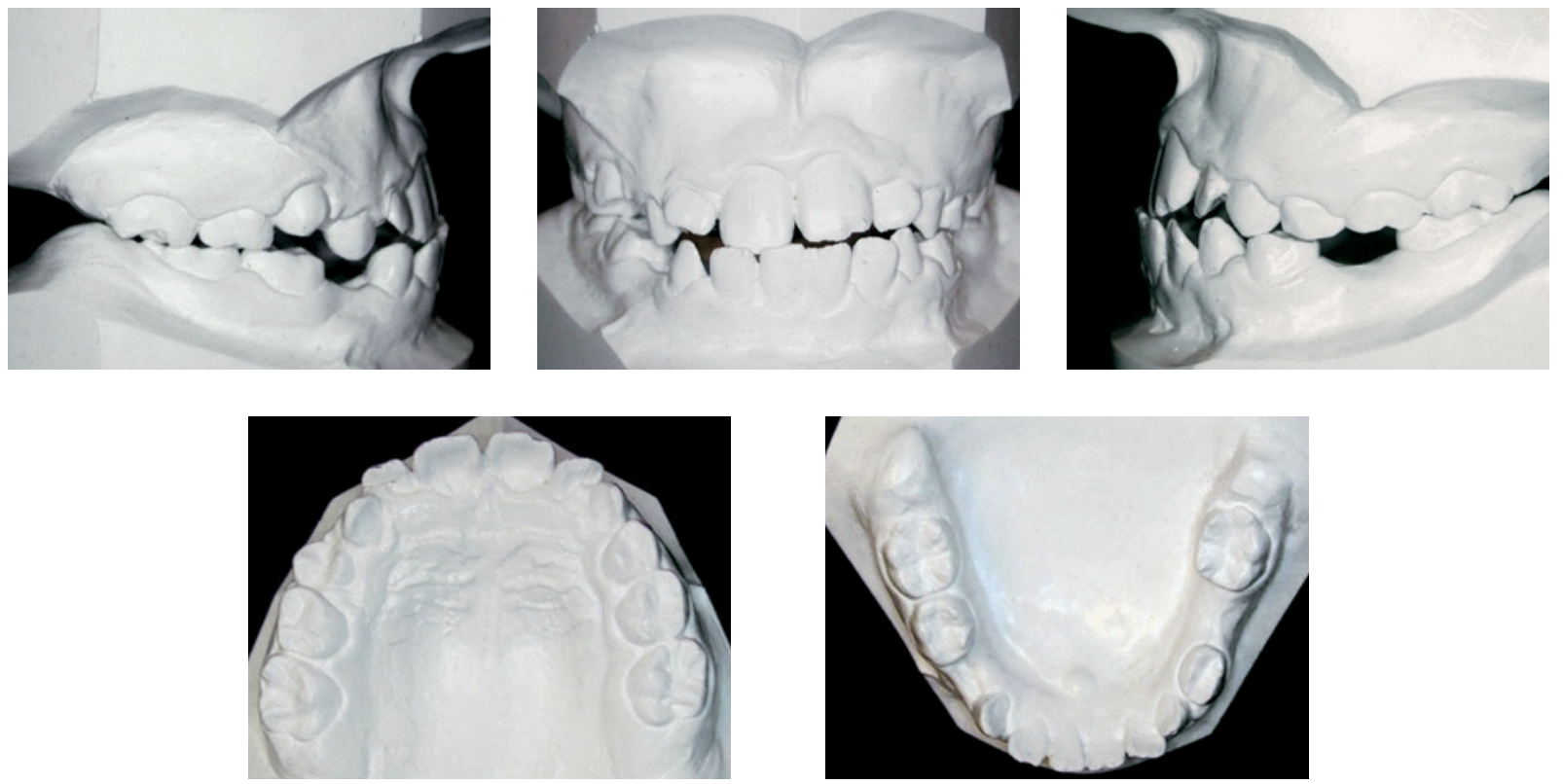

FIGURA 2 - Vistas laterais, frontal e oclusais dos modelos que foram apresentados aos alunos. 
de gesso (Fig. 1, 2). O caso clínico apresentava uma paciente com Classe III, subdivisão, com as seguintes características dentárias: mordida cruzada anterior, desalinhamento entre as linhas médias dentárias superior e inferior, apinhamento dentário e perda precoce de um dente decíduo, durante a fase da dentadura mista. Após analisarem o caso clínico apresentado, os alunos eram questionados, por meio de perguntas fechadas, quanto à classificação de Angle, à existência de problemas dentários, à fase ideal para o início do tratamento e sua possível indicação para o especialista. As respostas do questionário foram mantidas em sigilo, para preservar a identidade dos alunos.

Os dados coletados foram processados e analisados com o auxílio do programa Epilnfo 6.04. Como o objetivo deste trabalho foi avaliar o grau de conhecimento ortodôntico dos alunos de graduação, a análise foi descritiva e comparativa.

\section{RESULTADOS}

Analisando a distribuição da amostra, foi possível perceber que houve uma certa dificuldade por parte dos alunos em detectar a Classe III de Angle unilateral, uma vez que somente, aproximadamente, metade dos alunos classificou corretamente o caso ( $n=69$ ou 49,6\%). Enquanto 52 alunos classificaram como Classe III bilateral e 4 como sendo uma Classe II unilateral (Gráf. 1).

Como pode ser observado no gráfico 2 , o desvio de linha média foi identificado por $90 \%$ ( $\mathrm{n}=$ 124). Em relação à mordida cruzada anterior, foi

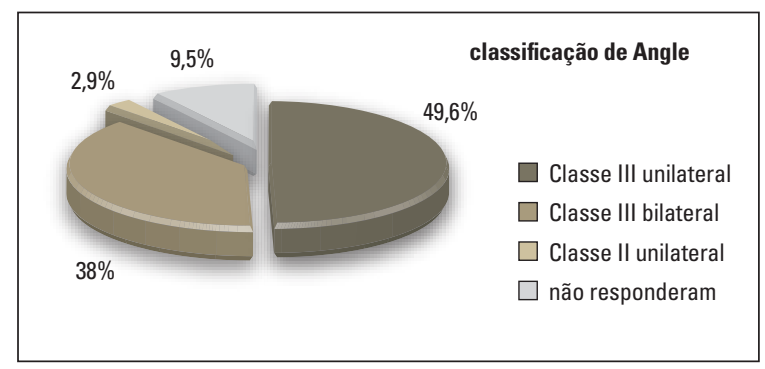

GRÁFICO 1 - Gráfico setorial avaliando a classificação de Angle segundo a amostra de alunos de graduação em Odontologia do estado do Rio de Janeiro. observado que 122 alunos (89\%) verificaram sua existência. $\mathrm{O}$ apinhamento dentário foi diagnosticado por 101 alunos $(73,7 \%)$ e 63 destes (46\%) notaram a presença da perda precoce do dente decíduo, enquanto 35 alunos $(25,6 \%)$ reconheceram a presença de mordida cruzada posterior unilateral e $21(15,3 \%)$ observaram a presença de mordida aberta, características estas ausentes no caso clínico, ratificando a dificuldade de diagnóstico encontrada pelos estudantes.

Ao serem indagados sobre a necessidade de tratamento ortodôntico, somente $5,1 \%$ da amostra responderam que não haveria necessidade e 0,7\% não respondeu à pergunta (Gráf. 3).

Quanto à fase ideal para iniciá-lo, considerando-se a idade dentária, 57,5\% dos alunos optaram pela fase de dentadura decídua. No entanto, para $35 \%$, a fase indicada seria o fim da dentadura mista e 6,6\% dos alunos acreditaram que a dentadura permanente seria a fase correta para se iniciar a terapia ortodôntica, como demonstra o gráfico 4 . Contudo, considerando-se a idade esquelética, o surto puberal de crescimento pareceu importante para grande parte da amostra, sendo que: para $53,3 \%$ deles, o tratamento deveria ser realizado antes do surto; para $38,7 \%$, durante; e para $4,8 \%$, quando o paciente não tivesse mais potencial de crescimento. Apenas 2,2\% consideraram que o tratamento da Classe III de Angle não depende do surto de crescimento, podendo ser realizado em qualquer época, como exposto no gráfico 5.

As respostas dos alunos provenientes de esco-

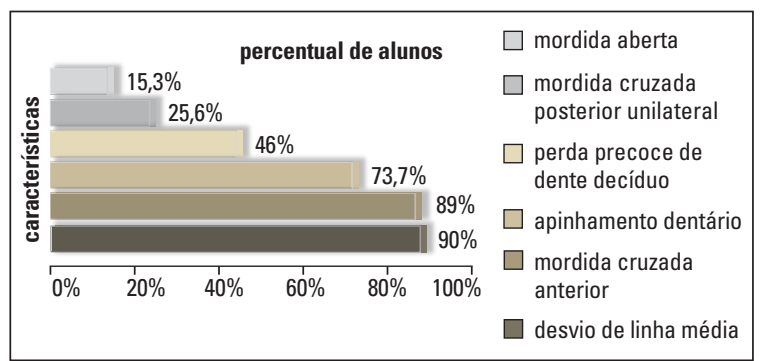

GRÁFICO 2 - Gráfico de barras listando as características da oclusão do caso clínico apresentado, reconhecidas pela amostra dos alunos de graduação em Odontologia do estado do Rio de Janeiro. 


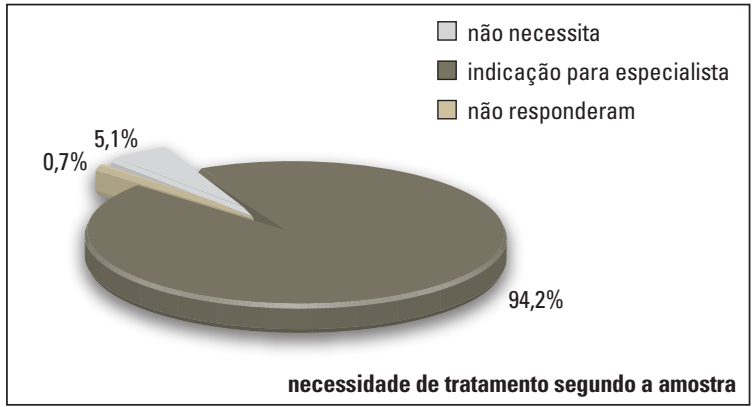

GRÁFICO 3 - Gráfico setorial avaliando a necessidade de tratamento do caso apresentado, segundo a amostra de alunos de graduação em Odontologia do estado do Rio de Janeiro.

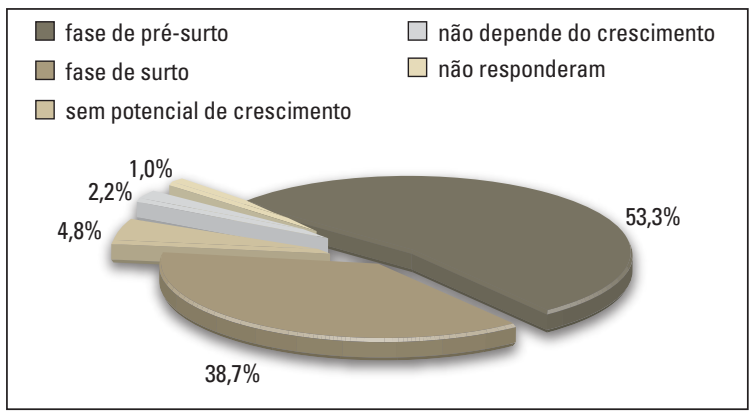

GRÁFICO 5 - Gráfico setorial avaliando o momento ideal para tratamento ortodôntico de pacientes Classe III de Angle, considerando-se a idade esquelética, segundo a amostra dos alunos de graduação em Odontologia do estado do Rio de Janeiro.

las com atividades clínicas e laboratoriais foram comparadas com aquelas que só recebem treinamento laboratorial e não foram encontradas diferenças significativas. Também não foram encontradas diferenças significativas nas respostas quando os alunos foram agrupados por escolas de origem.

\section{DISCUSSÃO}

A formação ortodôntica obtida em cursos brasileiros de graduação apresenta um conteúdo variado, de acordo com a linha de pensamento de cada universidade. Entretanto, esta deveria enfocar principalmente o ensino do desenvolvimento da oclusão normal, assim como o crescimento esquelético dos ossos faciais, fornecendo o embasamento necessário para que seja possível o diagnóstico de anormalidades nas dentaduras e

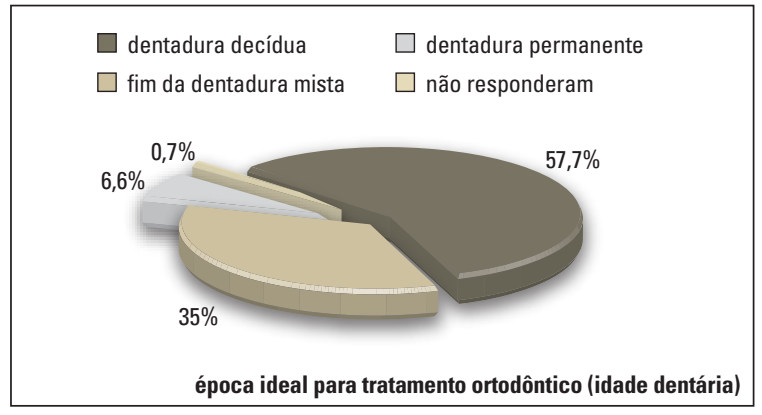

GRÁFICO 4 - Gráfico setorial avaliando a fase ideal para tratamento ortodôntico de pacientes Classe III de Angle, considerando-se a idade dentária, segundo a amostra de alunos de graduação em Odontologia do estado do Rio de Janeiro.

desvios no padrão normal de crescimento.

A avaliação da formação educacional em nível de graduação tem sido uma preocupação antiga dos educadores e dentistas em outros países. A Associação Americana das Faculdades de Odontologia desenvolveu, em 1980, o Guia Curricular para Ortodontia, com o intuito de ditar um conteúdo de programas para o ensino da Ortodontia, abrangendo informações suficientes para que haja, por parte dos alunos, um reconhecimento e uma atuação frente às más oclusões, selecionando casos de Ortodontia interceptativa e indicando os demais para especialistas.

Jacobs ${ }^{11}$, no ano de 1979, identificou deficiências na formação de clínicos-gerais, não somente no diagnóstico dos problemas ortodônticos, mas também na identificação do momento ideal de tratamento das diversas más oclusões e nas indicações para especialistas.

No presente estudo, embora os alunos não fossem identificados, suas faculdades de origem eram registradas, com o objetivo de comparar e estabelecer possíveis tendências, de acordo com a escola de formação. Isto porque os currículos variam de conteúdo, podendo inclusive não constar treinamento clínico na Disciplina de Ortodontia. Assim, algumas faculdades contam apenas com aulas teóricas e atividades laboratoriais e outras têm também uma clínica específica para Ortodontia. Algumas escolas fazem este treinamento em conjunto com a Odontopediatria ou Clínica 
Integrada, que nem sempre contam com a mesma equipe de professores de Ortodontia. No entanto, surpreendentemente, não foram encontradas diferenças significativas nas respostas quando os alunos foram agrupados por escolas de origem.

Miguel et al. ${ }^{16}$, em 2005, utilizaram a mesma amostra do presente trabalho, no entanto, utilizando um caso de um paciente com Classe I de Angle na "fase do patinho feio" (oclusão normal). Os estudantes identificaram habilmente que se tratava de uma má oclusão de Classe I ( $\mathrm{n}=120$ ou 87\%), a existência de diastemas foi percebida por $112(81,2 \%)$ e a sobremordida exagerada foi diagnosticada por 40 alunos (29\%). A relevância neste estudo foi que, quando a amostra foi questionada quanto à necessidade de tratamento, somente $10,1 \%$ entenderam que o tratamento ortodôntico não era necessário, visto que a oclusão era totalmente compatível com a fase de desenvolvimento. Os resultados demonstraram que grande parte nos alunos não detinha conhecimento adequado, não sendo capaz de identificar, no último período de graduação, as características normais do desenvolvimento, o que pode levar à indicação de tratamentos desnecessários.

O presente trabalho também detectou a mesma tendência destes alunos, os quais apresentaram dificuldades em identificar corretamente a má oclusão de Classe III de Angle unilateral e a perda precoce do dente decíduo, assim como em determinar a época correta de intervenção terapêutica. No entanto, a grande maioria dos entrevistados conseguiu perceber com facilidade a existência do desalinhamento entre as linhas médias dentárias superior e inferior e a presença da mordida cruzada anterior, evidenciando que problemas na região anterior são mais perceptíveis.

Estes dados contrapõem-se ao fato de que o diagnóstico e o tratamento precoce da Classe III de Angle são de fundamental importância, na grande maioria dos casos, para a efetiva correção desta (sem que seja necessária a intervenção cirúrgica futura) ou, ao menos, para a redução da severidade da deformidade facial, que ocorreria com o crescimento, caso não houvesse tratamento, proporcionando uma melhora das relações oclusais, faciais e psicossociais ${ }^{2}$.

A abordagem ortodôntica da Classe I (na qual há um bom relacionamento das bases ósseas com a base do crânio e um mau relacionamento dentário) pode ser realizada na dentadura permanente, procedendo uma terapia de etapa única. O tratamento da Classe II se faz mais favorável quando realizado durante o surto de crescimento puberal do indivíduo, geralmente associado à fase final da dentadura mista. Já a Classe III é mais preocupante, pois a época ideal de tratá-la é antes do surto ${ }^{27}$. Clínicos-gerais e odontopediatras têm contato com pacientes em idade mais precoce do que o ortodontista, sendo, portanto, de fundamental importância saber se estes profissionais são capazes de identificar a Classe III, para orientar os responsáveis sobre o do tratamento a ser realizado.

Sabe-se que este estudo apresenta limitações frente a todos os outros critérios que deveriam ser aplicados para se avaliar o ensino da Ortodontia no estado do Rio de Janeiro. No entanto, diante das evidências encontradas, sugere-se que estudos de maior abrangência sejam realizados, com o objetivo de verificar a necessidade de modificação do enfoque dado aos conteúdos programáticos de Ortodontia. Suspeita-se que grande atenção é dada às técnicas para confecção de aparelhos ortodônticos, em detrimento do ensino do diagnóstico, discussão e elaboração de planos de tratamento.

\section{CONCLUSÕES}

A partir destes dados, pode-se constatar que existe uma deficiência dos alunos de graduação das universidades do estado do Rio de Janeiro em identificar a Classe III de Angle, assim como há, também, uma dificuldade quanto ao reconhecimento da época ideal para intervenção e indicação do paciente ao ortodontista. 
Ao revelar estas deficiências, acredita-se na fomentação de iniciativas que objetivem alterar o conteúdo programático dos cursos de Ortodontia, com a intenção de preparar profissionais mais bem qualificados, de modo a atuar criteriosamente no mercado de trabalho.

Enviado em: abril de 2005 Revisado e aceito: setembro de 2007

\title{
Class III malocclusion diagnosis by graduation students
}

\begin{abstract}
Aim: The aim of this article was to check the ability of undergraduate students to identify Class III malocclusion and also recognize the correct timing for referring them for orthodontic treatment, taking into consideration the patient's dental and skeletal ages. Methods: The sample included 138 senior students of 10 Dental Schools in the State of Rio de Janeiro, which answered a written questionnaire with objective questions. It was also presented to them the facial photographs and study models of a unilateral Class III patient, which also included other dental irregularities. Results: It could be observed that it was easy for most of the students to identify the dental midline deviation ( $n=124$ or $90 \%$ ) and the anterior crossbite $(n=122$ or $89 \%)$. However, approximately half of the sample ( $n=63$ or $46 \%$ of the students) was able to classify the studied clinical case as a unilateral Class III. Only $46 \%$ of the group $(n=63)$ could identify the early loss of a deciduous tooth. Almost the totality of the sample agreed on the orthodontic treatment need, however, it was hard for them to agree on the best timing for referring the case to the specialist and the beginning of this therapy. Conclusion: The students graduate in Dental School with difficulties on the correct diagnosis of Class III cases and are not fully aware of a basic protocol for the treatment of this abnormality.
\end{abstract}

Key words: Interceptive orthodontics. Diagnosis. Angle Class III malocclusion.

\section{REFERÊNCIAS}

1. AMERICAN Association of Dental Schools Curricular Guidelines for Orthodontics. J. Dent. Educ., Washington, D. C., v. 44, p. 223-225, 1980.

2. CAPELOZZA FILHO, L. et al. Tratamento ortodôntico da Classe III: revisando o método (ERM e tração, por meio de um caso clínico). Rev. Dental Press Ortodon. Ortop. Facial, Maringá, v. 7, n. 6, p. 99-119, nov./dez. 2002.

3. COELHO, U.; JIMÉNEZ, E. E.; OELLANA, B.; REAL, M. F. Ortodontia interceptadora viabilizando a correção da má oclusão de Classe III: caso clínico. J. Bras. Ortodon. Ortop. Facial, Curitiba, v. 9, n. 53, p. 53-55, set./out. 2004.

4. COHEN, M.; SILVERMAN, E. A new simple palate splitting device. J. Clin. Orthod., Boulder, v. 7, no. 6, p. 368-369, June 1973.

5. ELLIS, E.; McNAMARA JR., J. A. Components of adult Class III malocclusion. J. Oral Maxillofac. Surg., Philadelphia, v. 42, no. 5, p. 295-305, May 1994.

6. FRÄNKEL, R.; FRÄNKEL, C. H. Ortopedia orofacial como regulador de função. 1. ed. São Paulo: Ed. Santos, 1990.

7. GRABER, T. M.; VANARSDALL JÚNIOR, R. L. Ortodontia: princípios e técnicas atuais. 2. ed. Rio de Janeiro: GuanabaraKoogan, 1996.

8. GUYER, E. C. et al. Components of Class III malocclusion in juveniles and adolescent. Angle Orthod., Appleton, v. 56 , no. 1, p. 7-30, Jan. 1986.
9. HAAS, A. J. Palatal expansion just the beginning of dentofacial orthopedics. Am. J. Orthod., St. Louis, v. 57, no. 3, p. 219-255, Mar. 1970.

10. HICKHAN, J. H. Maxillary protraction therapy: diagnosis and treatment. J. Clin. Orthod., Boulder, v. 25, no. 2, p. 102-119, 1991.

11. JACOBS, R. M. Ten-year study of strategies for teaching clinical inference in predoctoral orthodontic education. J. Dent. Educ., Washington, D.C., v. 41, p. 477- 478, 1979.

12. KILICOGLU, H.; KIRLIC, Y. Profile changes in patients with Class III malocclusion after Delaire mask therapy. Am. J. Orthod. Dentofacial Orthop., St. Louis, v. 113, no. 4, p. 453-462, Apr. 1998.

13. MAJOR, P.; ELBADRAWY, E. H. Maxillary protraction for early orthopedic correction of skeletal Class III malocclusion. Pediatr. Dent., Chicago, v. 15, no. 3, p. 203-207, May/June 1993

14. McNAMARA JR., J. A. An orthopedic approach to the treatment of Class III malocclusion in young patients. J. Clin. Orthod., Boulder, v. 21, no. 9, p. 598-608, Nov. 1987.

15. MERWIN, D. et al. Timing for effective application of anteriorly directed orthopedic force to the maxilla. Am. J. Orthod. Dentofacial Orthop., St. Louis, v. 112, no. 3, p. 292-299, Sept. 1997.

16. MIGUEL, J. A. M. et al. Oclusão normal na dentadura mista: reconhecimento das características oclusais por alunos de graduação. Rev. Dental Press Ortodon. Ortop. Facial, Maringá, v. 10, n. 1, p. 59-66, jan./ fev. 2005. 
17. MITANI, $H$.; FURKAZAWA, $H$. Effects of chincap force on the timing and amount of mandibular growth associated with anterior reserved occlusion (Class III malocclusion) during puberty.

Am. J. Orthod. Dentofacial Orthop., St. Louis, v. 90, no. 6, p. $454-463,1986$.

18. NANDA, R. Biomechanical and clinical considerations of a modified protraction headgear. Am. J. Orthod., St. Louis, v. 28 , no. 2 , p. 125-139, 1980.

19. NGAN, P. et al. Treatment response to maxillary expansion and protraction. Eur. J. Orthod., Oxford, v. 18, no. 2, p. 151-168, Apr. 1996

20. OPPENHEIN, A. Possibility for physiologic orthodontic movement. Am. J. Orthod., St. Louis, v. 30, p. 345-368, 1944

21. PROFFIT, W. R. Ortodontia contemporânea. 2. ed. Rio de Janeiro: Guanabara-Koogan, 1995.

22. RITUCCI, R.; NANDA, R. The effect of chin cup therapy on the growth and development of the cranial base and midface. Am. J. Orthod. Dentofacial Orthop., St. Louis, v. 90, no. 6, p. 475-483, 1986.

23. SILVA FILHO, O. G. et al. Early treatment of Class III malocclusion with rapid maxillary expansion and maxillary protraction. Am. J. Orthod. Dentofacial Orthop., St. Louis, v. 113, no. 2, p. 196-203, 1998.
24. SILVA FILHO, O. G.: SANTOS, S. C. B. N.: SUGIMOTO, R. M. Má oclusão de Classe III: época oportuna de tratamento. Ortodontia, São Paulo, v. 28, n. 3, p. 74-84, set./dez. 1995

25. SUGAWARA, J. et al. Long-term effects of chincap therapy on skeletal profile in mandibular prognathism. Am. J. Orthod.

Dentofacial Orthop., St. Louis, v. 98, no. 2, p. 127-133, 1990.

26. SUNG, S. J.; BAIK, H. S. Assessment of skeletal and dental changes by maxillary protraction. Am. J. Orthod. Dentofacial Orthop., St. Louis, v. 114, no. 5, p. 492-502, 1998

27. TELLES, C. S. Má oclusão dentária e crescimento facial. In: CONGRESSO PAULISTA DE ODONTOLOGIA, 15., 1992, São Paulo. Anais... São Paulo [s.n.], 1992. p. 289-300.

28. TURLEY, P. K. Orthopedic correction of Class III malocclusion with palatal expansion and custom protraction headgear. J. Clin. Orthod., Boulder, v. 22, no. 5, p. 314-325, May 1988.

29. TURPIN, D. L. Early Class III treatment. In: AMERICAN ASSOCIATION OF ORTHODONTISTS, 81., 1981, San Francisco. Abstracts... San Francisco: AAO, 1981.

30. VIAZIS, A. D. Atlas of Orthodontics: principles and clinical applications. Philadelphia: Saunders, 1993
Endereço para correspondência

Cristiane Canavarro

Av. Ataulfo de Paiva, 204/ sala 510 - Leblon

CEP: 22.440-033 - Rio de Janeiro/RJ

E-mail: cristianecanavarro@gmail.com 